ఠ

Open Access Full Text Article

REVIEW

\title{
Neurogenic orthostatic hypotension in Parkinson's disease: evaluation, management, and emerging role of droxidopa
}

This article was published in the following Dove Press journal:

Vascular Health and Risk Management

3 April 2014

Number of times this article has been viewed

\section{Stuart H Isaacson \\ Julia Skettini}

Parkinson's Disease and Movement Disorders Center of Boca Raton, Boca Raton, FL, USA
Correspondence: Stuart H Isaacson Parkinson's Disease and Movement Disorders Center of Boca Raton, 95I NW 13th St Suite 5E, Boca Raton, FL 33486, USA

$\mathrm{Tel}+\mid 5613921818$

Fax + $56 \mid 3928989$

Email isaacson@parkinsonscenter.org
Abstract: Neurogenic orthostatic hypotension $(\mathrm{nOH})$ is due to failure of the autonomic nervous system to regulate blood pressure in response to postural changes due to an inadequate release of norepinephrine, leading to orthostatic hypotension and supine hypertension. $\mathrm{nOH}$ is common in Parkinson's disease (PD). Prevalence varies throughout the course of PD, ranging from $40 \%$ to $60 \%$, and resulting in symptomatic $\mathrm{nOH}$ in approximately half. Symptomatic $\mathrm{nOH}$, including lightheadedness, can limit daily activities and lead to falls. Symptomatic nOH can also limit therapeutic options for treating PD motor symptoms. Clinical evaluation should routinely include symptom assessment and blood pressure measurement of supine, sitting, and 3-minute standing; 24-hour ambulatory blood pressure monitoring can also be helpful. Non-pharmacological management of symptomatic nOH involves education, physical maneuvers, and adequate hydration. Current pharmacological treatment of symptomatic $\mathrm{nOH}$ includes salt supplement, fludrocortisone, midodrine, pyridostigmine, and other empiric medications. Despite these options, treatment of symptomatic nOH remains suboptimal, often limited by severe increases in supine blood pressure. Droxidopa, an oral prodrug converted by decarboxylation to norepinephrine, is a promising therapeutic option for symptomatic $\mathrm{nOH}$ in $\mathrm{PD}$, improving symptoms of $\mathrm{nOH}$, daily activities, falls, and standing systolic blood pressure in several recent trials. These trials demonstrated short-term efficacy and tolerability, with comparable increases in standing and supine blood pressures. Longer-term studies are ongoing to confirm durability of treatment effect.

Keywords: (pre)syncope, norepinephrine, autonomic, lightheadedness, treatment, falls

\section{Introduction}

Neurogenic orthostatic hypotension $(\mathrm{nOH})$ results from failure of the autonomic nervous system (ANS) to regulate blood pressure in response to postural change, due to an inadequate release of norepinephrine (NE). This leads to both orthostatic hypotension upon standing and supine hypertension when lying. $\mathrm{nOH}$ is a hallmark of several neurodegenerative diseases, including multiple systems atrophy, Parkinson's disease (PD), and primary autonomic failure. PD is the second most common neurodegenerative disease, and $\mathrm{nOH}$ is a commonly encountered clinical problem in patients with PD, perhaps affecting up to $40 \%-60 \%$ of patients throughout the multi-decade disease course. ${ }^{1-4}$ Symptomatic nOH occurs in approximately $20 \%$ of patients with $\mathrm{PD},{ }^{1,5}$ and increases with PD duration, disease severity, age, and levodopa usage. ${ }^{5}$ However, symptoms such as lightheadedness may be variable though the day, and may abate and recur over time. Thus, there is not always a consistent correlation between orthostatic lightheadedness/dizziness and finding orthostatic hypotension when blood 
pressure is measured at a single reading. Although several pharmacological and non-pharmacological options are available to help manage this condition, current treatment of symptomatic $\mathrm{nOH}$ remains suboptimal.

\section{Normal ANS response to standing}

Postural change (ie, standing or lying supine) induces gravitational redistribution of blood volume, leading to changes in blood pressure. Upon standing, pooling of venous blood in the legs is countered by the normal sympathetic ANS to maintain standing blood pressure. ${ }^{6}$ Lying supine also causes gravitational redistribution of blood volume, and the normal ANS minimizes blood pressure from rising too high. Norepinephrine is the major neurotransmitter in the ANS regulation of blood pressure in response to postural changes. ${ }^{7}$ Sympathetic activation in response to standing leads to: venoconstriction with increased venous return; an increase in heart rate and myocardial contractility with increased cardiac output; and vasoconstriction with increased blood pressure. Normal activation of the intact ANS, along with sufficient circulating blood volume, prevents the gravity-induced fall in standing systolic blood pressure (s-SBP), maintaining cerebral perfusion and of other vital organs. ${ }^{8}$

\section{Impaired ANS response to standing in $\mathrm{nOH}$}

In patients with $\mathrm{PD}$ and $\mathrm{nOH}$, autonomic dysfunction causes blood pressure to fall upon standing, due to an inappropriate $\mathrm{NE}$ response to postural change. Orthostatic hypotension has been defined as a drop in SBP of at least $20 \mathrm{mmHg}$ or a drop in diastolic blood pressure of at least $10 \mathrm{mmHg}$ after 3 minutes of standing. ${ }^{9}$ There is often a loss of the cardioacceleratory response too. ${ }^{10}$ Non-neurogenic causes of orthostatic hypotension are also common in patients with $\mathrm{PD}$, and contribute to blood pressure drop. ${ }^{11}$ These non-neurogenic causes of orthostatic hypotension should be identified first, and include dehydration, medications, and cardiac pump failure. A clinical diagnosis of $\mathrm{nOH}$ can be made when these non-neurogenic causes of persistent orthostatic hypotension are excluded, and can be confirmed through autonomic testing and plasma NE levels. ${ }^{12}$

In PD, autonomic dysfunction is mainly a result of cardiac sympathetic denervation with inadequate activation of $\mathrm{NE}$ pathways ${ }^{7,13-15}$ and also baroreflex failure ${ }^{16}$ This can emerge during the course of PD or can occur early in its course. ${ }^{17-20}$ Parkinsonism due to multiple system atrophy is also accompanied by prominent autonomic dysfunction, but nOH results from failure of central NE pathways. ${ }^{21,22}$

\section{Symptomatic nOH}

Upon standing, the normal ANS response maintains s-SBP within the range of cerebrovascular autoregulation. In $\mathrm{nOH}$, a fall in blood pressure upon standing may not cause symptoms if s-SBP does not drop too low so that cerebral perfusion is maintained. When blood pressure falls upon standing, compensatory cerebrovascular autoregulation may maintain (or partially maintain) cerebral perfusion, minimizing symptoms. ${ }^{23}$ Symptomatic nOH occurs when s-SBP falls below the range of cerebrovascular autoregulation, resulting in cerebral hypoperfusion and consequent lightheadedness/ dizziness or syncope.

Asymptomatic $\mathrm{nOH}$ can become symptomatic in response to worsening autonomic dysfunction or due to orthostatic stress. ${ }^{24}$ Indeed, in patients with $\mathrm{PD}, \mathrm{nOH}$ is often compounded by non-neurogenic causes of $\mathrm{OH}$ and by orthostatic stressors. Symptomatic nOH may only emerge in response to an orthostatic stressor. ${ }^{25}$ Mild dehydration can occur due to inadequate fluid intake, dysphagia, and concomitant diuretics. Early morning orthostasis may be problematic due to nocturnal supine fluid shifts. ${ }^{26}$ Postprandial hypotension can trigger symptomatic $\mathrm{nOH},{ }^{27,28}$ as can prolonged standing or walking. Increased vasodilation due to heat, alcohol, or other factors may cause symptoms of nOH to emerge..$^{29}$ Many medications can lower blood pressure, especially during times of orthostatic stress or at their peak effects, including antihypertensive and dopaminergic therapies for $\mathrm{PD}^{30-33}$ (Figure 1).

\section{Clinical evaluation of $\mathrm{nOH}$}

Routine clinical evaluation of patients with PD should always include an assessment of blood pressure (lying, sitting, and 3-minute standing). Although orthostatic hypotension is diagnosed with a reduction of s-SBP of at least $20 \mathrm{mmHg}$ within 3 minutes of standing, ${ }^{9}$ lesser drops in s-SBP may still be symptomatic, and orthostatic hypotension may not occur until beyond 3 minutes. ${ }^{34}$ Heart rate should normally rise 4-6 beats per minute upon standing, with a greater increase in response to orthostatic hypotension; with autonomic dysfunction, this cardioacceleratory response is typically blunted. ${ }^{9}$ Symptomatic nOH may not always correlate with isolated measurements of s-SBP, due to the diurnal circadian rhythm of blood pressure and also to the marked fluctuations in blood pressure that occur throughout the day. ${ }^{35}$ Twenty-four hour ambulatory blood pressure monitoring can be helpful in the evaluation of patients with symptomatic $\mathrm{nOH}$ to better understand temporal fluctuations in blood pressure, especially when clinical symptoms do not regularly correlate with sporadic blood pressure measurements. ${ }^{35}$ 


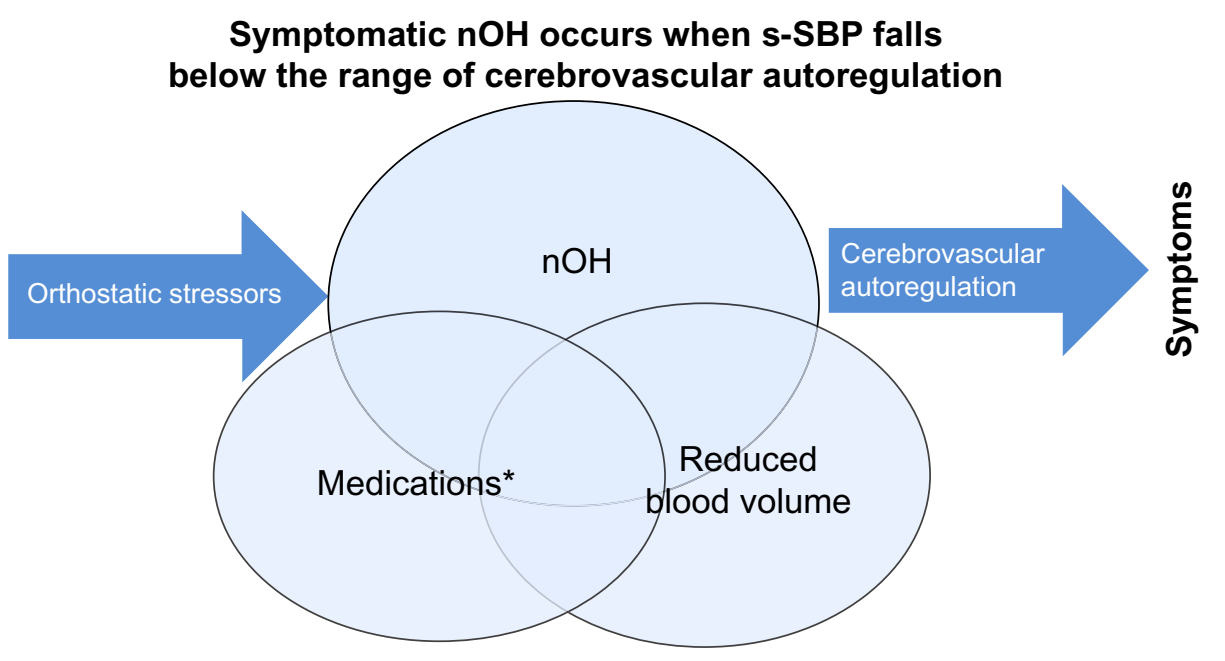

Figure I Overlapping causes of symptomatic $\mathrm{nOH}$ (Venn diagram): I) autonomic failure of NE pathways upon standing; 2) dopaminergic and other medications causing lower SBP; and 3) suboptimal hydration leading to reduced circulating blood volume.

Note: *Medications include dopaminergic, diuretics, central adrenergic inhibitors, alpha-I antagonists, nitrates.

Abbreviations: $\mathrm{nOH}$, neurogenic orthostatic hypotension; SBP, systolic blood pressure; s-SBP, standing SBP.

Medical history should query possible offending medications, daily activities, potential orthostatic stressors, and symptoms of $\mathrm{nOH}$. Common symptoms of $\mathrm{nOH}$ include lightheadedness, visual disturbances, impaired cognition, ${ }^{36}$ fatigue, sleepiness (ie, postprandial), and difficulty standing or walking; syncope and falls may also occur. Symptoms of inadequate perfusion of other organs can cause symptoms, such as upper back/neck pain. The Orthostatic Hypotension Questionnaire (OHQ) can be useful to monitor symptoms over time ${ }^{37}$ Distinguishing imbalance on standing (due to postural instability) from lightheadedness (due to $\mathrm{nOH}$ ) is important. ${ }^{38}$ Other stigmata of autonomic dysfunction may be present, including constipation, gastroparesis, and urinary frequency. ${ }^{39,40}$

Testing of ANS integrity may be a useful adjunct to clinical evaluation. Testing may include RR-interval variation, spectral analysis of RR interval and blood pressure ${ }^{20}$, Valsava response, thermoregulatory sweat test, tilt-table, and sampling plasma. ${ }^{11,21,41-43}$ MIBG scintigraphy has distinguished central and peripheral causes of $\mathrm{nOH}$, but is not readily available. In PD, reduced radioisotope uptake reflects the sympathetic cardiac denervation in PD. ${ }^{11,16,44}$

\section{Management of $\mathrm{nOH}$}

Patients with symptomatic $\mathrm{nOH}$ should be treated to improve clinical symptoms and to maintain daily activities, such as walking. Treatment will also reduce the risk of injury, falls, and other morbidities associated with $\mathrm{nOH}$. The treatment of symptomatic nOH is aimed at raising s-SBP into the range of compensatory cerebrovascular autoregulation.
Treatment is multifaceted. Clinical therapeutic decision making must be based on standing (not sitting) SBP measurements. All possible offending pharmacologic agents should be minimized or stopped. Effective management requires extensive patient education with a combination of non-pharmacological and pharmacological therapies ${ }^{24}$ (Figure 2).

Disease education of patients and their caregivers is directed towards an understanding of the role of postural changes on blood pressure, and is a necessary adjunct to clinical management. Rapid changes in posture should be avoided. Arising from supine to standing should be preceded by sitting for several minutes before standing. Standing after prolonged sitting should occur slowly, and several minutes of standing should precede walking. Patients also need to be advised that they should identify places to safely sit and rest in the case of unexpected symptom onset in order to avoid falls. ${ }^{45}$ Patients and caregivers should especially be educated about the impact of orthostatic stressors on $\mathrm{nOH}$ symptoms. ${ }^{24}$ Extended periods of standing or walking may result in symptoms, as can physical exercise, meals, ${ }^{27}$ and any rise in core body temperature (fever, hot shower, hot or dry climates)..$^{24,29}$

1. Decrease incidence and severity of symptoms;

2. Restore functional capacity for activities, including standing and walking;

3. Prevent severe drops in S-SBP in patients who fall or have episodes of syncope;

4. Minimize increases in supine blood pressure.

Figure 2 Treatment goals for patients with symptomatic $\mathrm{nOH}$.

Abbreviations: $\mathrm{nOH}$, neurogenic orthostatic hypotension; s-SBP, standing systolic blood pressure. 
Polypharmacy should be avoided, and all medications that have potential to lower blood pressure should be discontinued as possible. The use of diuretics and antihypertensives should be discouraged, although shorter-acting antihypertensives prior to bedtime may be needed for supine hypertension. ${ }^{10,24}$ Other concomitant therapies, including medications for depression (tricyclics), sleep/allergy (antihistamines), and urinary frequency (anticholinergics and alpha-adrenergic antagonists) should be minimized.

Dopaminergic medications also lower blood pressure. ${ }^{30,33}$ If motor symptoms of parkinsonism permit, modifying the Parkinson's medication regimen may be one way to minimize blood pressure fluctuations in patients with nOH. Levodopa dose may need to be fractionated if orthostatic symptoms occur at peak dose. Dopamine agonist dose, especially of the immediate-release formulations that have higher peaks, may need to be reduced. Selegiline, anticholinergics, and amantadine also commonly lower blood pressure.

Patient education is often combined with non-pharmacologic measures, and these are sometimes sufficient. Increased hydration and salt intake is essential to maintain sufficient circulating blood volume, although caution must be used in patients with congestive heart failure. In response to lightheadedness or other symptoms of nOH, immediately drinking a 12-16 ounce bolus of water can rapidly raise s-SBP. ${ }^{24,46,47}$ Instruction on physical maneuvers, such as toe-raises, crossing legs, squatting, and bending at the waist can also improve nOH symptoms when they occur. ${ }^{24,48}$ Body compression garments, corset or belt, and thigh-high compression stockings are useful, ${ }^{24,49,50}$ but may be difficult for some patients to routinely wear. Elevation of the head $30^{\circ}$ above horizontal will help minimize supine hypertension and nocturnal supine diuresis. ${ }^{26,51}$

Medication management of $\mathrm{nOH}$ is added when patients have persistent symptoms despite these non-pharmacological approaches. ${ }^{10}$ Fludrocortisone is a synthetic mineralocorticoid that acts to retain sodium and water. This increases circulating blood volume and consequently blood pressure ${ }^{51,52}$ Clinical effect of daily dosages of $0.1-0.4 \mathrm{mg}$ should be administered once (or twice) earlier in the day. Onset of effect typically occurs over a period of 3-7 days. Its use is limited by increased supine blood pressure, which must be monitored in patients by sitting and supine blood pressure evaluations. Routine monitoring of electrolytes should also be performed to evaluate for development of hypokalemia. Excessive fluid retention by fludrocortisone can result in pedal edema and congestive heart failure, and may limit its use.

Midodrine is an alpha-adrenergic agonist that can increase blood pressure by increasing peripheral vascular resistance. While some patients may respond to a dosage of $2.5 \mathrm{mg}$, most will require 5-10 $\mathrm{mg}$ dosage. ${ }^{53-55}$ Clinical response to a dose of midodrine should be assessed before and 1 hour after administration, as onset of action occurs within 30 minutes, peaks at 1 hour, and lasts 3-4 hours. ${ }^{53}$ Due to its short duration of clinical effect, midodrine is administered several times daily, but should not be given within several hours of bedtime or near other times of lying supine. ${ }^{53}$ Adverse effects of midodrine include piloerection, pruritus, and increased supine blood pressure, which can be dose limiting. ${ }^{55}$

Pyridostigmine has also been used to treat $\mathrm{nOH}$. Pyridostigmine is a peripheral inhibitor of acetylcholinesterase, which can cause a mild increase in standing blood pressure without significantly increasing supine blood pressure. ${ }^{56}$ Adverse effects are cholinergic, including diarrhea, excessive sweating, and siallorhea. When symptomatic nOH persists despite use of fludrocortisone, midodrine, and pyridostigmine, or the use of these medications are limited by adverse effects, several empiric medications have been tried. ${ }^{10,24}$ Erythropoietin can expand blood volume and increase blood pressure in symptomatic patients, but can increase supine blood pressure. ${ }^{57,58}$ Desmopressin, ${ }^{59}$ indomethacin, ${ }^{60}$ and caffeine $^{61}$ have been evaluated in small trials. In patients with persistent or severe symptomatic nOH, attempts to augment NE pathways through the use of sympathomimetics or of NE transporter inhibitors (ie, NE-transporter blockers, serotonin-NE reuptake inhibitors) have been tried with variable success. ${ }^{62-65}$

Droxidopa (L-threo-3-4-dihydroxyphenylserine [L-threo DOPS]), an oral prodrug converted by decarboxylation to NE in both the central and the peripheral nervous systems, ${ }^{66-68}$ is a promising therapeutic option for symptomatic $\mathrm{nOH}$ in $\mathrm{PD}$. Droxidopa improves $\mathrm{nOH}$ in $\mathrm{PD}$ by replenishing NE. ${ }^{67,69}$ Over more than two decades, studies in Japan ${ }^{70,71}$ and in Europe ${ }^{72}$ have studied the effects of droxidopa in patients with $\mathrm{nOH}$ and PD. In these trials, droxidopa has been demonstrated to increase s-SBP, even in patients taking a decarboxylase inhibitor. Smaller studies in the US have also found similar benefit in $\mathrm{nOH} .{ }^{67,73}$ Droxidopa for $\mathrm{nOH}$ has been marketed in Japan since 1989 for the indications of: 1) improvement of frozen gait and dizziness on standing in Parkinson's disease (Yahr stage III); 2) improvement of orthostatic hypotension, syncope, and dizziness on standing in Shy-Drager syndrome and familial amyloid polyneuropathy; and 3) improvement of orthostatic hypotension symptoms in the hemodialytic patient (dizziness, lightheaded feeling, dizziness on standing up, malaise, and weakness). In the US, a "new drug 
application" has been filed with the FDA, and is pending regulatory approval.

More recently, droxidopa has been evaluated in several Phase III clinical trials in the US to establish its efficacy and safety in treating symptomatic $\mathrm{nOH}$, including in patients with $\mathrm{nOH}$ associated with $\mathrm{PD}$. The results of these trials have been presented in abstract form, but have not yet been fully published. In these trials, efficacy was assessed primarily by the two-part OHQ: Orthostatic Hypotension Symptom Assessment (OHSA; Item 1: dizziness/lightheadedness) and Orthostatic Hypotension Daily Activity Scale. ${ }^{37}$

An initial trial utilized a withdrawal design and enrolled patients with $\mathrm{nOH}$ due to $\mathrm{PD}$, multiple systems atrophy, and other neurological disorders with $\mathrm{nOH}$. After open-label droxidopa titration, droxidopa responders were randomized to treatment with droxidopa or placebo for 2 weeks. While OHQ was significantly improved, the primary endpoint of OHSA Item 1 (dizziness/lightheadedness) was not met. ${ }^{74}$ In a second trial, patients with $\mathrm{nOH}$ were enrolled in an induction design study. After open-label droxidopa titration followed by 1 week washout, droxidopa responders were randomized to treatment with droxidopa or placebo for 1 week. Significant improvement over placebo was found for OHQ, including OHSA Item 1 (dizziness/lightheadedness), and for s-SBP. ${ }^{75}$ A subsequent 3-month open-label study enrolled patients from these two trials. Overall, patients maintained stable scores on OHQ and OHSA Item 1 (dizziness/lightheadedness) for up to 12 months. However, a randomized 2-week withdrawal after 3 months of openlabel treatment did not find significant difference in $\mathrm{OHQ}$ between droxidopa and placebo, ${ }^{76}$ perhaps suggesting a prolonged residual effect of droxidopa. In a safety study, patients were evaluated with 24-hour ambulatory blood pressure monitoring 1 week after droxidopa washout and again after 4 weeks of droxidopa treatment. Droxidopa treated patients had a significantly greater increase in mean daytime SBP without causing sustained elevations in supine SBP overnight. ${ }^{77}$ Long-term, open-label treatment with droxidopa has also been reported with overall good tolerability and safety. ${ }^{78}$

Droxidopa has also been evaluated for symptomatic $\mathrm{nOH}$ in 225 patients with PD, one of the largest studies conducted of $\mathrm{nOH}$ in PD. After 1 week of randomized droxidopa or placebo treatment, there was a significant improvement in OHSA Item 1 (dizziness/lightheadedness), s-SBP, and clinician global improvement. ${ }^{79,80}$ At week 8, numerical differences persisted but were not statistically significant. Some patients had a reduction in falls, ${ }^{81}$ and treatment effect was
1. Monitor 3-minute-SBP, sitting blood pressure, supine blood pressure, and heart rate

2. Minimize polypharmacy

3. Postural adjustment, physical maneuvers, and elevate head of bed

4. Education and avoidance of orthostatic stressors (dehydration, meals, and heat)

5. Compression garments, water bolus

6. Expansion of circulating blood volume

a. Hydration

b. Salt

c. Fludrocortisone (monitor potassium, edema, and supine blood pressure)

7. Current pharmacotherapy
a. Midodrine
b. Pyridostigmine
c. Empiric medications

8. Emerging pharmacotherapy a. Droxidopa

Figure 3 Management of symptomatic $\mathrm{nOH}$.

Abbreviations: $\mathrm{nOH}$, neurogenic orthostatic hypotension; s-SBP, standing systolic blood pressure.

seen despite use of decarboxylase inhibitor, ${ }^{82}$ dopaminergic medications for $\mathrm{PD},{ }^{83}$ or prior use of midodrine. ${ }^{84}$

Overall, droxidopa has demonstrated short-term efficacy on symptoms of nOH and on s-SBP, including in patients with $\mathrm{PD}^{85}$ In long-term open-label treatment, droxidopa had good tolerability and safety, without significant supine hypertension. While some studies found sustained improvements in symptoms and s-SBP, longer-term studies are needed to confirm the durability of droxidopa treatment on $\mathrm{nOH}$ symptoms.

\section{Summary}

$\mathrm{nOH}$ in $\mathrm{PD}$ is due to an inadequate release of NE resulting in failure of the ANS to maintain s-SBP. nOH is common and can become symptomatic when compensatory cerebrovascular autoregulation cannot maintain adequate cerebral perfusion upon standing, often in response to orthostatic stress. Clinical evaluation of symptoms and 3-minute s-SBP should routinely be performed, so that treatment can be instituted to improve symptoms, daily activities, and reduce risk of injury, falls, and other morbidities (Figure 3). Current treatments for $\mathrm{nOH}$ are suboptimal and can increase supine blood pressure. Droxidopa is an emerging therapy for symptomatic $\mathrm{nOH}$, and increases s-SBP without greater increases in supine hypertension.

\section{Disclosure}

Stuart Isaacson received honoraria for CME, consultancy and research grants, and/or promotional speaking on behalf of Abbvie, Acadia, Adamas, Addex, Allergan, Allon, Astra Zeneca, Biotie, Britannia, Chelsea Therapeutics, 
Civitas, Eisai, GE, GSK, Impax, Ipsen, Kyowa, Lilly, Merck Schering-Plough, Medtronics, Merz, Michael J Fox Foundation, Novartis, Neurocrine, NIH, Novartis, Orion, Parkinson Study Group, Phytopharm, Purdue, Roche, Santhera, Serono, Shire, Teva, UCB, and US World Meds. Julia Skettini has no conflicts of interests in this work.

\section{References}

1. Senard JM, Rai S, Lapeyre-Mestre M, et al. Prevalence of orthostatic hypotension in Parkinson's disease. J Neurol Neurosurg Psychiatry. 1997;63(5):584-589.

2. Allcock LM, Ullyart K, Kenny RA, Burn DJ. Frequency of orthostatic hypotension in a community based cohort of patients with Parkinson's disease. J Neurol Neurosurg Psychiatry. 2004;75(10):1470-1471.

3. Sithinamsuwan P, Orrawanhanothai P, Thithum K, et al. Orthostatic hypotension: a non-motor complication assessment in 82 patients with idiopathic Parkinson's disease in Phramongkutklao Hospital. J Med Assoc Thai. 2010;93 Suppl 6:S93-S99.

4. Jain S, Goldstein DS. Cardiovascular dysautonomia in Parkinson disease: from pathophysiology to pathogenesis. Neurobiol Dis. 2012;46(3):572-580.

5. Ha AD, Brown CH, York MK, Jankovic J. The prevalence of symptomatic orthostatic hypotension in patients with Parkinson's disease and atypical parkinsonism. Parkinsonism Relat Disord. 2011;17(8): $625-628$.

6. Mathias CJ. To stand on one's own legs. Clin Med. 2002;2(3): 237-245.

7. Sharabi Y, Imrich R, Holmes C, Pechnik S, Goldstein DS. Generalized and neurotransmitter-selective noradrenergic denervation in Parkinson's disease with orthostatic hypotension. Mov Disord. 2008;23(12):1725-1732.

8. Schatz IJ. Orthostatic hypotension. I. Functional and neurogenic causes. Arch Intern Med. 1984;144(4):773-777.

9. Freeman R, Wieling W, Axelrod FB, et al. Consensus statement on the definition of orthostatic hypotension, neurally mediated syncope and the postural tachycardia syndrome. Clin Auton Res. 2011;21(2):69-72.

10. Freeman R. Clinical practice. Neurogenic orthostatic hypotension. N Engl J Med. 2008;358(6):615-624.

11. Senard JM, Pathak A. Neurogenic orthostatic hypotension of Parkinson's disease: what exploration for what treatment? Rev Neurol (Paris). 2010;166(10):779-784.

12. Goldstein DS, Sharabi Y. Neurogenic orthostatic hypotension: a pathophysiological approach. Circulation. 2009;119(1):139-146.

13. Goodall MC, Harlan WR Jr, Alton H. Decreased noradrenaline (norepinephrine) synthesis in neurogenic orthostatic hypotension. Circulation. 1968;38(3):592-603.

14. Goldstein DS, Polinsky RJ, Garty M, et al. Patterns of plasma levels of catechols in neurogenic orthostatic hypotension. Ann Neurol. 1989;26(4):558-563.

15. Imrich R, Eldadah BA, Bentho O, et al. Functional effects of cardiac sympathetic denervation in neurogenic orthostatic hypotension. Parkinsonism Relat Disord. 2009;15(2):122-127.

16. Sharabi Y, Goldstein DS. Mechanisms of orthostatic hypotension and supine hypertension in Parkinson disease. J Neurol Sci. 2011;310(1-2): $123-128$.

17. Bonuccelli U, Lucetti C, Del Dotto P, et al. Orthostatic hypotension in de novo Parkinson disease. Arch Neurol. 2003;60(10):1400-1404.

18. Milazzo V, Di Stefano C, Servo S, Zibetti M, Lopiano L, Maule S. Neurogenic orthostatic hypotension as the initial feature of Parkinson disease. Clin Auton Res. 2012;22(4):203-206.

19. Kaufmann H, Nahm K, Purohit D, Wolfe D. Autonomic failure as the initial presentation of Parkinson disease and dementia with Lewy bodies. Neurology. 2004;63(6):1093-1095.
20. Oka H, Toyoda C, Yogo M, Mochio S. Cardiovascular dysautonomia in de novo Parkinson's disease without orthostatic hypotension. Eur J Neurol. 2011;18(2):286-292.

21. Goldstein DS, Holmes C, Sharabi Y, Brentzel S, Eisenhofer G. Plasma levels of catechols and metanephrines in neurogenic orthostatic hypotension. Neurology. 2003;60(8):1327-1332.

22. Goldstein DS, Holmes C, Patronas N, Kopin IJ. Cerebrospinal fluid levels of catechols in patients with neurogenic orthostatic hypotension. Clin Sci (Lond). 2003;104(6):649-654.

23. Schatz IJ. Orthostatic hypotension. II. Clinical diagnosis, testing, and treatment. Arch Intern Med. 1984;144(5):1037-1041.

24. Low PA, Singer W. Management of neurogenic orthostatic hypotension: an update. Lancet Neurol. 2008;7(5):451-458.

25. Ziemssen T, Reichmann H. Cardiovascular autonomic dysfunction in Parkinson's disease. J Neurol Sci. 2010;289(1-2):74-80.

26. Omboni S, Smit AA, van Lieshout JJ, Settels JJ, Langewouters GJ, Wieling W. Mechanisms underlying the impairment in orthostatic tolerance after nocturnal recumbency in patients with autonomic failure. Clin Sci (Lond). 2001;101(6):609-618.

27. Lipsitz LA, Ryan SM, Parker JA, Freeman R, Wei JY, Goldberger AL. Hemodynamic and autonomic nervous system responses to mixed meal ingestion in healthy young and old subjects and dysautonomic patients with postprandial hypotension. Circulation. 1993;87(2):391-400.

28. Lipsitz LA, Pluchino FC, Wei JY, Minaker KL, Rowe JW. Cardiovascular and norepinephrine responses after meal consumption in elderly (older than 75 years) persons with postprandial hypotension and syncope. Am J Cardiol. 1986;58(9):810-815.

29. Pathak A, Lapeyre-Mestre M, Montastruc JL, Senard JM. Heatrelated morbidity in patients with orthostatic hypotension and primary autonomic failure. Mov Disord. 2005;20(9):1213-1219.

30. Senard JM, Brefel-Courbon C, Rascol O, Montastruc JL. Orthostatic hypotension in patients with Parkinson's disease: pathophysiology and management. Drugs Aging. 2001;18(7):495-505.

31. Meco G, Pratesi L, Bonifati V. Cardiovascular reflexes and autonomic dysfunction in Parkinson's disease. J Neurol. 1991;238(4): 195-199.

32. Lang AE. Acute orthostatic hypotension when starting dopamine agonist therapy in parkinson disease: the role of domperidone therapy. Arch Neurol. 2001;58(5):835.

33. Wood LD. Clinical review and treatment of select adverse effects of dopamine receptor agonists in Parkinson's disease. Drugs Aging. 2010;27(4):295-310.

34. Jamnadas-Khoda J, Koshy S, Mathias CJ, Muthane UB, Ragothaman M, Dodaballapur SK. Are current recommendations to diagnose orthostatic hypotension in Parkinson's disease satisfactory? Mov Disord. 2009;24(12):1747-1751.

35. Stuebner E, Vichayanrat E, Low DA, Mathias CJ, Isenmann S, Haensch CA. Twenty-four hour non-invasive ambulatory blood pressure and heart rate monitoring in Parkinson's disease. Front Neurol. 2013;4:49.

36. Poda R, Guaraldi P, Solieri L, et al. Standing worsens cognitive functions in patients with neurogenic orthostatic hypotension. Neurol Sci. 2012;33(2):469-473.

37. Kaufmann H, Malamut R, Norcliffe-Kaufmann L, Rosa K, Freeman R. The Orthostatic Hypotension Questionnaire (OHQ): validation of a novel symptom assessment scale. Clin Auton Res. 2012;22(2): 79-90.

38. Hillen ME, Wagner ML, Sage JI. "Subclinical" orthostatic hypotension is associated with dizziness in elderly patients with Parkinson disease. Arch Phys Med Rehabil. 1996;77(7):710-712.

39. Camilleri M, Malagelada JR, Stanghellini V, Fealey RD, Sheps SG. Gastrointestinal motility disturbances in patients with orthostatic hypotension. Gastroenterology. 1985;88(6):1852-1859.

40. Cersosimo MG, Benarroch EE. Autonomic involvement in Parkinson's disease: pathology, pathophysiology, clinical features and possible peripheral biomarkers. J Neurol Sci. 2012;313(1-2):57-63. 
41. Kopin IJ, Polinsky RJ, Oliver JA, Oddershede IR, Ebert MH. Urinary catecholamine metabolites distinguish different types of sympathetic neuronal dysfunction in patients with orthostatic hypotension. J Clin Endocrinol Metab. 1983;57(3):632-637.

42. Low PA, Tomalia VA, Park KJ. Autonomic function tests: some clinical applications. J Clin Neurol. 2013;9(1):1-8.

43. Gurevich TY, Groozman GB, Giladi N, Drory VE, Hausdorff JM, Korczyn AD. R-R interval variation in Parkinson's disease and multiple system atrophy. Acta Neurol Scand. 2004;109(4):276-279.

44. Haensch CA, Lerch H, Jorg J, Isenmann S. Cardiac denervation occurs independent of orthostatic hypotension and impaired heart rate variability in Parkinson's disease. Parkinsonism Relat Disord. 2009;15(2):134-137.

45. Smit AA, Wieling W, Opfer-Gehrking TL, van Emmerik-Levelt HM, Low PA. Patients' choice of portable folding chairs to reduce symptoms of orthostatic hypotension. Clin Auton Res. 1999;9(6):341-344.

46. Jordan J, Shannon JR, Black BK, et al. The pressor response to water drinking in humans: a sympathetic reflex? Circulation. 2000;101(5): 504-509.

47. Z'Graggen WJ, Hess CW, Humm AM. Acute fluid ingestion in the treatment of orthostatic intolerance - important implications for daily practice. Eur J Neurol. 2010;17(11):1370-1376.

48. Bouvette CM, McPhee BR, Opfer-Gehrking TL, Low PA. Role of physical countermaneuvers in the management of orthostatic hypotension: efficacy and biofeedback augmentation. Mayo Clin Proc. 1996;71(9):847-853.

49. Smit AA, Wieling W, Fujimura J, et al. Use of lower abdominal compression to combat orthostatic hypotension in patients with autonomic dysfunction. Clin Auton Res. 2004;14(3):167-175.

50. Podoleanu C, Maggi R, Brignole M, et al. Lower limb and abdominal compression bandages prevent progressive orthostatic hypotension in elderly persons: a randomized single-blind controlled study. J Am Coll Cardiol. 2006;48(7):1425-1432.

51. van Lieshout JJ, ten Harkel AD, Wieling W. Fludrocortisone and sleeping in the head-up position limit the postural decrease in cardiac output in autonomic failure. Clin Auton Res. 2000;10(1):35-42.

52. Hickler RB, Thompson GR, Fox LM, Hamlin JT 3rd. Successful treatment of orthostatic hypotension with 9-alpha-fluorohydrocortisone. N Engl J Med. 1959;261:788-791.

53. Wright RA, Kaufmann HC, Perera R, et al. A double-blind, doseresponse study of midodrine in neurogenic orthostatic hypotension. Neurology. 1998;51(1):120-124.

54. Jankovic J, Gilden JL, Hiner BC, et al. Neurogenic orthostatic hypotension: a double-blind, placebo-controlled study with midodrine. Am J Med. 1993;95(1):38-48.

55. Low PA, Gilden JL, Freeman R, Sheng KN, McElligott MA. Efficacy of midodrine vs placebo in neurogenic orthostatic hypotension. A randomized, double-blind multicenter study. Midodrine Study Group. JAMA. 1997;277(13):1046-1051.

56. Singer W, Sandroni P, Opfer-Gehrking TL, et al. Pyridostigmine treatment trial in neurogenic orthostatic hypotension. Arch Neurol. 2006;63(4):513-518

57. Perera R, Isola L, Kaufmann H. Effect of recombinant erythropoietin on anemia and orthostatic hypotension in primary autonomic failure. Clin Auton Res. 1995;5(4):211-213.

58. Hoeldtke RD, Streeten DH. Treatment of orthostatic hypotension with erythropoietin. N Engl J Med. 1993;329(9):611-615.

59. Mathias CJ, Fosbraey P, da Costa DF, Thornley A, Bannister R. The effect of desmopressin on nocturnal polyuria, overnight weight loss, and morning postural hypotension in patients with autonomic failure. Br Med J (Clin Res Ed). 1986;293(6543):353-354.

60. Abate G, Polimeni RM, Cuccurullo F, Puddu P, Lenzi S. Effects of indomethacin on postural hypotension in Parkinsonism. $\mathrm{Br}$ Med $\mathrm{J}$. 1979;2(6203):1466-1468.

61. Onrot J, Goldberg MR, Biaggioni I, Hollister AS, Kingaid D, Robertson D. Hemodynamic and humoral effects of caffeine in autonomic failure. Therapeutic implications for postprandial hypotension. N Engl J Med. 1985;313(9):549-554.
62. Lahrmann H, Cortelli P, Hilz M, Mathias CJ, Struhal W, Tassinari M. EFNS guidelines on the diagnosis and management of orthostatic hypotension. Eur J Neurol. 2006;13(9):930-936.

63. Onrot J, Goldberg MR, Biaggioni I, Wiley RG, Hollister AS, Robertson D. Oral yohimbine in human autonomic failure. Neurology. 1987;37(2):215-220.

64. Fouad-Tarazi FM, Okabe M, Goren H. Alpha sympathomimetic treatment of autonomic insufficiency with orthostatic hypotension. Am J Med. 1995;99(6):604-610.

65. Okamoto LE, Shibao C, Gamboa A, et al. Synergistic effect of norepinephrine transporter blockade and alpha- 2 antagonism on blood pressure in autonomic failure. Hypertension. 2012;59(3):650-656.

66. Freeman R, Landsberg L. The treatment of orthostatic hypotension with dihydroxyphenylserine. Clin Neuropharmacol. 1991;14(4):296-304.

67. Kaufmann H, Saadia D, Voustianiouk A, et al. Norepinephrine precursor therapy in neurogenic orthostatic hypotension. Circulation. 2003;108(6):724-728.

68. Goldstein DS. L-Dihydroxyphenylserine (L-DOPS): a norepinephrine prodrug. Cardiovasc Drug Rev. 2006;24(3-4):189-203.

69. Kaufmann H. Could treatment with DOPS do for autonomic failure what DOPA did for Parkinson's disease? Neurology. 1996;47(6): 1370-1371.

70. Narabayashi H, Nakanishi T. Therapeutic effects of L-DOPS in Parkinson's disease, double-blind comparative study against placebo as control in patients with long-term levodopa therapy. Clin Eval. 1987;15: 423-457.

71. Yanagisawa N, Ikeda S, Hashimoto T, et al. [Effects of L-threo-Dops on orthostatic hypotension in Parkinson's disease]. No To Shinkei. 1998;50(2):157-163. Japanese.

72. Mathias CJ, Senard JM, Cortelli P. A double-blind, randomized, placebocontrolled study to determine the efficacy and safety of droxidopa in the treatment of orthostatic hypotension associated with multiple system atrophy and Parkinson's disease. Clin Auton Res. 2007;17:272.

73. Goldstein DS, Holmes C, Kaufmann H, Freeman R. Clinical pharmacokinetics of the norepinephrine precursor L-threo-DOPS in primary chronic autonomic failure. Clin Auton Res. 2004;14(6):363-368.

74. Kaufmann H, Mathias C, Freeman R, Low P, Biaggioni I, the Droxidopa Study Group. Treatment with droxidopa - a phase III multinational, placebo-controlled, parallel group, withdrawal-design study in subjects with neurogenic orthostatic hypotension and non-diabetic autonomic neuropathy. Clin Auton Res. 2009;19:281.

75. Kaufmann H, Freeman R, Biaggioni I, Low P, Pedder S, Hewitt A, Mathias C. Treatment of neurogenic orthostatic hypotension: results from a multi-center, double-blind, randomized, placebo-controlled, parallel group, induction design study. Neurology. 2012;78:PL02.001.

76. Isaacson S, Shill H, Vernino S, Cioffi C, Hutchman R. Durability of effect with long-term, open-label droxidopa treatment in patients with symptomatic neurogenic orthostatic hypotension (NOH 303). Mov Disord. 2012;27:S424-S425.

77. Kaufmann H, Klos K, Hutchman R, Isaacson S. Effects of droxidopa (Northera $^{\mathrm{TM}}$ ) on 24 hour blood pressure (BP) in patients with symptomatic neurogenic orthostatic hypotension (NOH). Mov Disord. 2010;25: S405-S406.

78. Shill H, Vernino S, Hutchman R, Adkins L, Isaacson S. A multicenter, open-label study to assess the long-term safety of droxidopa in patients with symptomatic neurogenic orthostatic hypotension (NOH 304). Mov Disord. 2012;27:S428.

79. Isaacson SH, Hauser RA, Szakacs CBN, Cioffi CC. Droxidopa treatment impact on orthostatic symptoms and standing systolic blood pressure in patients with Parkinson's disease and symptomatic neurogenic orthostatic hypotension: Study 306. Neurology. 2013;80:Emerging Science Abstract 010.

80. Isaacson S, Hauser RA, Szakacs CBN, Cioffi CC. Impact of droxidopa treatment in patients with Parkinson's disease and symptomatic neurogenic orthostatic hypotension (study 306). Mov Disord. 2013 28 Suppl 1:468. 
81. Hauser RA, Schwieterman W, Isaacson S. Impact of treatment with droxidopa in repeat fallers with Parkinson's disease and symptomatic neurogenic orthostatic hypotension (NOH 306A). Mov Disord. 2012;27:S423.

82. Biaggioni I, Low P, Rowse G, Kaufmann H. Analysis of efficacy in patients with symptomatic neurogenic orthostatic hypotension treated with droxidopa and dopa-decarboxylase inhibitors. Mov Disord. 2012;27: S422-S423.

83. LeWitt P, Gorny S. Analysis of efficacy and safety outcomes in patients treated with droxidopa in combination with other drug classes. Mov Disord. 2012;27:S425-S426.
84. Low P, Nelson J, Stacy M. Safety and efficacy of droxidopa in patients previously treated with midodrine. Mov Disord. 2012;27:S426.

85. Mathias C, Low P, Freeman R, Hewitt L, Kaufmann H. Integrated efficacy analysis of droxidopa in 2 double-blind, placebo-controlled Phase 3 studies in patients with neurogenic orthostatic hypotension. Mov Disord. 2012;27:S426.

\section{Publish your work in this journal}

Vascular Health and Risk Management is an international, peerreviewed journal of therapeutics and risk management, focusing on concise rapid reporting of clinical studies on the processes involved in the maintenance of vascular health; the monitoring, prevention and treatment of vascular disease and its sequelae; and the involvement of metabolic disorders, particularly diabetes. This journal is indexed on PubMed Central and MedLine. The manuscript management system is completely online and includes a very quick and fair peer-review system, which is all easy to use. Visit http://www.dovepress.com/ testimonials.php to read real quotes from published authors.

Submit your manuscript here: http://www.dovepress.com/vascular-health-and-risk-management-journal 